Article

\title{
Drug Use Control Perception and Strategies in General and Clinical Population in a Spanish City
}

\author{
Salvador Amigo ${ }^{1 *}$ and Angela Beleña ${ }^{1}$
}

1 Department of Personality, Evaluation and Psychological Treatments, Faculty of Psychology, University of Valencia, 46010 Valencia, Spain; mangeles.belena@uv.es

* Correspondence: salvador.amigo@uv.es

\begin{abstract}
Background: This article evaluates the perception of drug use control and strategies in Valencia City (Spain) in a general and clinical population, in two independent studies. Material and Methods: 1071 people participated. In the Study $1(n=924)$ the entire sample came from general population (GP), and in the Study 2 ( $n=147)$, 68 were drug users being treated in an Addictive Behaviors Unit (ABU), and 79 people of the GP. The drug use control perception and strategies in both subgroups were compared. The participants filled in the Drug Use Strategies Scale and a Drug Use Survey. Results: A high level of perception of drug control in GP was obtained ( $72,7 \%$ in the Study 1 and $67,5 \%$ in the Study 2), and $32.5 \%$ in ABU subgroup. People in the PG and drug users in treatment differ in some control strategies. A predictive profile of the perception of control was obtained for the Study 2. Conclusion: The high degree of perception of controlling drug use in the GP, and partially in drug users being treated, and the specific control strategies reported suggests that moderate use and drug control strategies are a great value alternative to bear in mind compared to abstinence.
\end{abstract}

Keywords: drugs; perception of controlling drug use; drug use control strategies; moderate drug use; risk and harm reduction approach

\section{Introduction}

There is growing evidence that controlled drug use is more the rule than the exception, and that personal control is relevant even in cases of addiction [1]. Zinberg in [2] argues that controlled drug use is the result of not only the social context in which drugs are taken, but also of attitudes to drugs, learnt self-control skills and personality factors. Thus the social context in which drugs are used favours controlled use, and encourages social rituals and sanctions of unsuitable or high-risk drug use.

Community studies conducted with large samples of heavy cocaine drug users and other drugs around the world have shown that controlled cocaine use is very frequent, which refutes the myth of the "inevitability of the climb from drug use to addiction" [312].

One of these studies defines "controlled use" as "a self-controlled use pattern that does not derive from any significant social dysfunction in, for example, any alteration in skills to assume the roles and responsibilities in daily living" [11] (p. 33).

Several authors have also described the strategies that are most widely used by users of all kinds of drugs [13-16]. For instance, it has been verified that cocaine users can enhance their drug use control by following certain rules [17], such as: 1) do not use drugs 
on a daily basis; 2) set rules as to how and when to use drugs; 3) do not commercialise drugs, etc.

Vadhan et al. in [18] checked that heavy cocaine users were able to make a decision about not using drugs if they were offered an alternative, like money. Other studies conducted in the San Francisco Bay Area and in Sweden with frequent users of cannabis and other drugs have verified that drug users also adopt rational criteria to control their drug use, by acting normally in their day-to-day lives, and by reducing possible risks and harm caused by drugs $[19,20]$.

Another research line consisted in creating and applying scales to assess drug control strategies. The Protective Behavioral Strategies Scale (PBSS) is a 20-item scale that presents alcohol management strategies. It was created using information about the alcohol management strategies found in the scientific literature, on reports about alcohol users, particularly university students, and on experts in this study area. In line with the perspective of reducing risks and harm caused by drugs, this scale evaluates adopting certain strategies to reduce the harm caused by drinking alcohol [21,22]. A high PBSS score is associated with less alcohol use and fewer problems related with alcohol [e.g., 21,23-25].

A study into drug use strategies [26] asked young people form Valencia (Spain) if they thought it was possible to control drug use by adopting certain strategies and, if they thought it was, which strategies did they think were the most useful ones. This was done using the Drug Use Strategies Scale (DUSS). Of the 724 youths who answered the question, $471(65 \%)$ responded YES and $253(35 \%)$ NO. Of the 17 proposed strategies, the most highly valued were: strategy 1 ("Do not use drugs on a daily basis"), 4 ("Do not use drugs to sort out my problems or faults"), 8 ("Do not use drugs to escape from reality"), 12 ("Reduce the amount of drug"), 14 ("Keep my mind occupied and do other things when I feel like using drugs") and 17 ("Think about the negative personal and health consequences").

Fewer studies are available on drug control strategies adopted by users being treated. For instance, Lin and Zhang in [27] conducted a study in a rehabilitation center in Shanghai, where patients participated in in-depth interviews about their synthetic drug use. Users reported that they adopted control strategies, e.g., selecting and using drugs according to their own experience and in line with friends' suggestions; controlling doses; limiting doses by spacing them in time and avoiding coming into contact with heavy drug users; trusting in the group's rules to avoid overdoses; enjoying the positive effects of the drug more.

This article aimed to confirm the first results obtained with the DUSS, and to also verify if drug users being treated are in favour of adopting drug use strategies or not compared with a sample of users from the general population.

Our main hypothesis is that the results on the perception of drug use control that have been obtained in numerous cities around the world, as we have mentioned previously, and that have been obtained in a sample of first-year university students in the city of Valencia (Spain) [26] will be replicated in this study with a broader and more diversified sample. The second hypothesis refers to the fact that we will find a percentage of drug users with a lower perception of drug use control than in the general population, but significant one, in such a way that the harm and risk reduction approach as an alternative to abstinence in these drug users must be considered.

Knowledge of the perception of controlling drug use and preferred control strategies provides relevant information about the resources available to drug users to handle drug 
use and will offer valuable information for professionals to design efficient prevention and/or intervention programs.

\section{Materials and Methods}

\subsection{Participants}

This article presents two studies: 924 volunteers participated in the Study 1, and 147 volunteers participated in the Study 2 . The whole sample was composed by 1.071 volunteers, all of them from Valencia city (Spain).

In the Study 2 two samples were compared. The first sample was made up of 68 drug users being treated in the Addictive Behaviors Unit (ABU). The second sample was formed by 79 people from the general population (GP), that they were not drug users or that they were not or had not been treated for drug addiction.

Table 1 offers data on age, level of education and gender, which correspond to each group in both studies. In order to present the collected results, in this table and the following ones, we will present the materials and method for the two studies together.

Table 1. Gender, age, and level of education of the participants in this study $(n=1.071)$

\begin{tabular}{|c|c|c|c|c|c|c|c|}
\hline & & \multirow{2}{*}{\multicolumn{2}{|c|}{ ESTUDY $1(n=924)$}} & \multicolumn{4}{|c|}{ ESTUDY $2(n=147)$} \\
\hline & & & & \multicolumn{2}{|c|}{ ABU $(n=68)$} & \multicolumn{2}{|c|}{ GP $(n=79)$} \\
\hline \multirow{2}{*}{ GENDER } & Male & \multicolumn{2}{|c|}{$357(38.6)$} & \multicolumn{2}{|c|}{$46(67.6)$} & \multicolumn{2}{|c|}{$42(53.2)$} \\
\hline & Female & \multicolumn{2}{|c|}{$567(61.4)$} & \multicolumn{2}{|c|}{$22(32.4)$} & \multicolumn{2}{|c|}{$37(46.8)$} \\
\hline \multirow{6}{*}{ STUDIES } & No qualifications & \multicolumn{2}{|c|}{$53(5.7)$} & \multicolumn{2}{|c|}{$5(7.4)$} & \multicolumn{2}{|c|}{0} \\
\hline & $\begin{array}{l}\text { Secondary } \\
\text { education }\end{array}$ & \multicolumn{2}{|c|}{$273(29.5)$} & \multicolumn{2}{|c|}{$38(55.9)$} & \multicolumn{2}{|c|}{$15(19)$} \\
\hline & Vocational training & \multicolumn{2}{|c|}{$168(18.2)$} & \multicolumn{2}{|c|}{$19(27.9)$} & \multicolumn{2}{|c|}{$22(27.8)$} \\
\hline & University & \multicolumn{2}{|c|}{$430(46.5)$} & \multicolumn{2}{|c|}{$6(8.8)$} & \multicolumn{2}{|c|}{$42(53.2)$} \\
\hline & \multirow{2}{*}{ AGE } & Mean & $S D$ & Mean & $S D$ & Mean & $S D$ \\
\hline & & 28.10 & 11.18 & 38.99 & 9.77 & 32.99 & 11.87 \\
\hline
\end{tabular}

ABU: Addictive Behavior Unit; GP: General Population. Percentages are in brackets.

In Study 1 we can see a higher percentage of women $(61.4 \%)$ than men $(38.6 \%)$, an average age of $28.10(\mathrm{SD}=11.18)$, with almost half being university students $(46.5 \%)$.

In the Study 2 the sample included a higher percentage of males than females for both the ABU (67.6\% and 32.4\%, respectively) and GP (53.2\% and $46.8 \%$, respectively) subgroups. Ages were somewhat older in the ABU than in the GP. For level of education, we can clearly see a higher level of education in the GP subgroup, with $53.2 \%$ as opposed to $8.8 \%$ of university students in the ABU subgroup.

So, the participants in Study 1 are younger than those in Study 2, and also have a higher percentage of women and university students. Due to the fact that the $n$ is quite different in both studies ( $n=924$ in Study 1 and $n=147$ in Study 2), and the participants in the Study 1 totally came from General Population, the comparisons between the general 
and clinical samples will only be carried out in Study 2, that was planned with that objective ( $n=79$ for GP subgroup and $n=68$ for ABU subgroup).

\subsection{Instruments}

- Drug Use Strategies Scale (DUSS) [26]. It includes 17 drug use control strategies, which must be answered by those who positively responded to this question: "Some people say that they control drug use because they do certain things that moderate drug use or reduce risks. Do you believe that it is possible to moderate, control or reduce drug use in general (those considered "hard" and "soft", legal or illegal) by doing certain things or employing certain strategies?"

- $\quad$ Drugs Survey following the European Monitoring Centre for Drugs and Drug Addiction (EMCDDA) criteria [28]. It is a brief self-report questionnaire, which measures the frequency of drugs use (such as cannabis, alcohol, tobacco, cocaine, MDMA, sedatives, hallucinogens and amphetamines).

\subsection{Inclusion criteria for participation and obtaining the sample}

The participants in the ABU subgroup had to fulfil drug use/drug addiction diagnosis criteria and be treated. The other subgroup (the GP) was obtained by the "snowball" method from the GP. None of these participants had ever been on treatment and did not fulfil the drug use/drug addiction diagnosis criteria. The same criteria were used in Study 1.

All subjects gave their informed consent for inclusion before they participated in the study. The study was conducted in accordance with the Declaration of Helsinki, and the protocol was approved by the Ethics Committee of the University of Valencia (Spain) in 2017 (Proyect identification code: H1484824011097).

\section{Results}

Table 2 shows the numbers and percentages of the participants who had used drugs sometime in their life, such as cannabis, ecstasy, cocaine, amphetamines and hallucinogens, for all groups. For Study 2 it also provides the Chi-square test results, which compare the frequencies of both subgroups. In all the analyses, 0 boxes indicate an expected frequency below 5, thus applying the Chi-square test was appropriate.

Table 2. Taken drugs sometime in their life for the three groups of this study

\begin{tabular}{cccccc}
\hline & & \multicolumn{4}{c}{ Sometime in their life } \\
\cline { 3 - 6 } & & \multicolumn{5}{c}{ ESTUDY 2 } \\
\cline { 3 - 6 } & ESTUDY 1 & TOTAL & ABU & GP & $\chi^{2}$ (Sig.) \\
\hline Cannabis & $339(69.2)$ & $100(68)$ & $54(79.4)$ & $46(58.2)$ & $7.54(.005)$ \\
\hline Ecstasy & $167(18.1)$ & $43(29.3)$ & $34(50)$ & $9(11.4)$ & $26.32(.000)$ \\
\hline Cocaine & $217(23.5)$ & $67(45.6)$ & $55(80.9)$ & $12(15.2)$ & $63.58(.000)$ \\
\hline Amphetamine & $121(13.1)$ & $39(26.5)$ & $35(51.5)$ & $4(5.1)$ & $40.37(.000)$ \\
\hline Hallucinogens & $178(19.3)$ & $47(32)$ & $34(50)$ & $13(16.5)$ & $19.90(.000)$ \\
\hline
\end{tabular}

Addictive Behaviors Unit; GP: General Population. Percentages are in brackets. 
Participants in Study 1 (who all come from the general population) have somewhat higher percentages of drug use sometime in their life than those in the GP subgroup in Study 2, and for all drugs, but lower than those of the ABU subgroup.

For Study 2 use of drugs some time in their life was higher for the ABU subgroup than for the GP subgroup for all the drugs. The Chi-square test was significant for all drugs. In both subgroups, the highest percentage corresponded to cannabis.

Table 3 offer drug use data (levels of drug use in one's life, in the last 12 months and in the last month, as percentages) for all study groups.

Table 3. Levels of drug use in one's life, in the last 12 months and in the last month.

\begin{tabular}{|c|c|c|c|c|c|c|c|c|c|c|c|c|}
\hline \multirow[t]{2}{*}{ DRUGS } & & \multicolumn{3}{|c|}{$\begin{array}{c}\text { How often in } \\
\text { your life }\end{array}$} & \multicolumn{4}{|c|}{$\begin{array}{c}\text { How often in the last } \\
12 \text { months }\end{array}$} & \multicolumn{4}{|c|}{$\begin{array}{c}\text { How often in the last } \\
\text { month }\end{array}$} \\
\hline & & $1-5$ & $6-30$ & $>\mathbf{3 0}$ & $\mathbf{0}$ & $1-5$ & $6-30$ & $>\mathbf{3 0}$ & $\mathbf{0}$ & $1-5$ & $6-30$ & $>\mathbf{3 0}$ \\
\hline \multirow{3}{*}{ Cannabis } & STUDY 1 & 34.4 & 19.2 & 45.9 & 45 & 21.1 & 12.2 & 21.4 & 64.3 & 16.4 & 7 & 12.1 \\
\hline & \multirow{2}{*}{ STUDY $2 \frac{\mathrm{ABU}}{\mathrm{GP}}$} & 18.5 & 13 & 68.5 & 40.7 & 16.7 & 29.6 & 59.3 & 66.7 & 13 & 5.6 & 14.8 \\
\hline & & 28.3 & 28.3 & 43.5 & 58.7 & 26.1 & 8.7 & 6.5 & 80.4 & 10.9 & 8.7 & 0 \\
\hline \multirow{3}{*}{ Ecstasy } & STUDY 1 & 50.9 & 29.3 & 19.8 & 59.3 & 29.9 & 7.8 & 3 & 88 & 9.6 & 1.8 & 0.6 \\
\hline & \multirow{2}{*}{ STUDY $2 \frac{\mathrm{ABU}}{\mathrm{GP}}$} & 38.2 & 23.5 & 38.2 & 88.2 & 8.8 & 2.9 & 0 & 97.1 & 2.9 & 0 & 0 \\
\hline & & 77.8 & 11.1 & 11.1 & 55.6 & 44.4 & 0 & 0 & 88.9 & 11.1 & 0 & 0 \\
\hline \multirow{3}{*}{ Cocaine } & STUDY 1 & 37.8 & 24.4 & 37.3 & 48.4 & 29.5 & 14.3 & 7.8 & 79.2 & 13.1 & 3.7 & 0.9 \\
\hline & \multirow{2}{*}{ STUDY $2 \frac{A B U}{G P}$} & 5.5 & 7.3 & 87.3 & 45.5 & 16.4 & 9.1 & 29.1 & 78.2 & 18.2 & 1.8 & 1.8 \\
\hline & & 50 & 25 & 25 & 75 & 16.7 & 8.3 & 0 & 91.7 & 8.3 & 0 & 0 \\
\hline \multirow{3}{*}{ Amphetamine } & STUDY 1 & 47.1 & 29.8 & 23.1 & 59.5 & 24 & 12.4 & 4.1 & 81.8 & 14.9 & 3.3 & 0 \\
\hline & \multirow{2}{*}{ STUDY $2 \frac{\mathrm{ABU}}{\mathrm{GP}}$} & 25.7 & 22.9 & 51.4 & 82.9 & 14.3 & 0 & 2.9 & 94.3 & 5.7 & 0 & 0 \\
\hline & & 75 & 0 & 25 & 50 & 25 & 25 & 0 & 50 & 50 & 0 & 0 \\
\hline \multirow{3}{*}{ Hallucinogen } & STUDY 1 & 66.3 & 25.3 & 8.4 & 67.4 & 25.3 & 7.3 & 0 & 87.1 & 12.4 & 0.6 & 0 \\
\hline & \multirow{2}{*}{ STUDY $2 \frac{\mathrm{ABU}}{\mathrm{GP}}$} & 44.1 & 23.5 & 32.4 & 94.1 & 5.9 & 0 & 0 & 100 & 0 & 0 & 0 \\
\hline & & 84.6 & 7.7 & 7.7 & 92.3 & 7.7 & 0 & 0 & 100 & 0 & 0 & 0 \\
\hline
\end{tabular}

ABU: Addictive Behaviors Unit. GP: General Population.

We can see how the participants in Study 1 have used drugs more recently (in the last year and in the last month) than the participants in the GP subgroup of Study 2, especially cannabis, ecstasy and cocaine.

For Study 2 we can see, drug use in one's life (>30 times) is clearly higher for the ABU subgroup than for the GP subgroup, and for all drugs, although this difference is somewhat smaller for cannabis. Use of drugs in the last 12 months is also higher for the ABU subgroup members compared to the GP ones. However, their drug uses in the last month do not differ that much as the ABU group members are being treated.

Table 4 offer the percentage of participants who consider that it is possible to adopt certain strategies to control drug use. 
Table 4. Perception of drug use control for the whole sample

\begin{tabular}{|c|c|c|c|c|c|c|}
\hline \multirow{2}{*}{$\begin{array}{c}\text { CONTROL } \\
\text { STRATEGIES }\end{array}$} & \multirow[t]{2}{*}{ STUDY 1} & \multicolumn{5}{|c|}{ STUDY 2} \\
\hline & & TOTAL & $\mathrm{ABU}$ & GP & $\chi^{2}$ (Sig.) & $\begin{array}{c}\text { Contingency } \\
\text { coefficient } \\
\text { (Sig.) }\end{array}$ \\
\hline YES & $672(72.7)$ & $83(56.5)$ & $27(32.5)$ & 56 (67.5) & & \\
\hline $\mathrm{NO}$ & $252(27.3)$ & 64 (43.5) & $41(64.1)$ & 23 (35.9) & $14.45(.000)$ & $.299(.000)$ \\
\hline
\end{tabular}

Percentages are in brackets. ABU: Addictive Behavior Unit; GP: General Population.

The highest percentage of perception of drug use control was obtained in Study 1 (72.7\%).

For the Study $2(n=147)$ it was $56.5 \%$. When we compared both study subgroups, the percentage of participants who responded YES in the GP group doubled this response in the ABU group (67.5\% and $32.5 \%$, respectively). The Chi-square test and the contingency coefficient were significant.

If we look at these results in proportion terms, of those subjects who answered YES, the probability of finding people in the GP group was 1.79 higher than in the ABU group; alternatively of the people who answered NO, it was 3.60 times more like-ly to find people in the GP group than in the ABU one.

It is worth stressing that although the percentage of $\mathrm{ABU}$ subgroup members was lower than that which corresponded to the GP subgroup, it was striking that $32.5 \%$ thought that it was possible to control drug use by adopting certain strategies.

Next a binary logistic regression analysis was done to determine which variables predicted perceived control. To this end, perceived control was considered a dependent variable, while group and gender are dichotomous variables that contains precisely two values (drug users being treated versus general population for group, and female and male for gender), age, level of education, and having used drugs sometime in one's life were the independent variables.

For the level of education variable, three dummy variables were created. As most of the participants had used several of the drugs contemplated herein more than once in their life, these variables could correlate. So analyses were previously done of tolerance and VIF (variance inflation factors) to rule out the effect of collinearity.

The level of tolerance of all the independent variables was above 0.10 , and the VIF values were under 10, which indicates no collinearity among the independent variables.

Then a hierarchical binary logistic regression analysis was done. As the inde-pendent variables, the first block included the epidemiological variables, while using drugs sometime in one's life was included in the second block.

In block 0, the overall statistics (sig.<.0005) indicated that there was a relation between the independent variables and the dependent variable. The analysis was done in two steps, with a Nagelkerke $\mathrm{R}^{2}$ of .277 and .324 , respectively. The final analysis results are shown in Table 5. 
Table 5. Results of the hierarchical binary logistic regression analysis.

\begin{tabular}{cllll}
\hline Variables & B & Wald & Sig. & Exp(B) \\
\hline Group & -1.891 & 9.061 & .003 & .151 \\
Age & -.040 & 4.484 & .034 & .961 \\
Gender & 1.123 & 6.230 & .013 & 3.075 \\
Education & -.079 & 2.88 & .409 & .877 \\
Cannabis & 1.118 & 4.423 & .035 & 3.058 \\
Ecstasy & -.056 & .008 & .928 & .945 \\
Cocaine & .076 & .012 & .914 & 1.079 \\
Amphetamine & -.763 & 1.385 & .239 & .466 \\
Hallucinogen & -.037 & .003 & .956 & .964 \\
\hline
\end{tabular}

As the education variable was not significant, it was not necessary to include the dichotomous variables that derived from the categorical variable.

The logit of perception of control was: a) 1.12 times higher for males (the odds ratio of having perception of control in males was 3.075 times higher than not having perception of control); b) 1.89 higher for the GP group; c) 0.40 higher for older people; d) 1.11 higher for those who had used cannabis sometime in their life

The variables that better explain perception of control are those with higher $\operatorname{Exp}(\mathrm{B})$ : gender and having used cannabis once in their life.

Next the participants who answered YES to the question about possibly controlling drugs by adopting certain strategies were selected ( $n=672$ for Study 1 and $n=83$ for Study 2). For Study 2, 27 belonged to the ABU subgroup and 56 to the GP subgroup. These were the participants who later indicated which strategies on the list of 17 strategies they thought were useful. Table 6 indicates the frequencies and percentages that corresponded to both studies, as well as the results of the Chi-square test and the contingency coefficient for the ABU-GP comparisons of Study 2.

Table 6. Favourable views (in percentages) of using some of 17 drug use control strategies for all groups

\begin{tabular}{|c|c|c|c|c|c|c|}
\hline & \multirow[b]{2}{*}{ CONTROL STRATEGIES } & \multirow[b]{2}{*}{$\begin{array}{l}\text { STUDY } 1 \\
(n=672)\end{array}$} & \multicolumn{4}{|c|}{ STUDY 2} \\
\hline & & & $\begin{array}{c}\text { ABU } \\
(n=27)\end{array}$ & $\begin{array}{c}\text { GP } \\
(n=56)\end{array}$ & $\chi^{2}$ (Sig.) & $\begin{array}{c}\text { Contingency } \\
\text { coefficient }\end{array}$ \\
\hline 1. & Not taken on a daily basis & $620(92.3)$ & $20(74.1)$ & $52(92.9)$ & $5.59(.018)$ & .25 \\
\hline 2 & $\begin{array}{l}\text { Only taken in certain places or with } \\
\text { certain people }\end{array}$ & $408(60.7)$ & $15(55.6)$ & $35(63.6)$ & $.49(.48)$ & .07 \\
\hline 3 & Do not sell drugs & $526(78.3)$ & $18(66.7)$ & $49(87.5)$ & $5.08(.024)$ & .24 \\
\hline 4 & $\begin{array}{l}\text { Do not use drugs to overcome my } \\
\text { problems or faults }\end{array}$ & $603(89.7)$ & $20(74.1)$ & $53(94.6)$ & $7.27(.007)$ & .28 \\
\hline 5 & $\begin{array}{l}\text { Only take orally or by snorting (if } \\
\text { cocaine is used) }\end{array}$ & $154(22.9)$ & $10(37)$ & $14(25)$ & $1.28(.257)$ & .12 \\
\hline
\end{tabular}




\begin{tabular}{|c|c|c|c|c|c|c|}
\hline 6 & $\begin{array}{l}\text { Alternate drug use with other } \\
\text { activities (walking, reading, etc.) }\end{array}$ & $496(73.8)$ & $18(66.7)$ & $49(87.5)$ & $5.08(.024)$ & .24 \\
\hline 7 & $\begin{array}{l}\text { Subordinating my obligations to } \\
\text { drug use (getting up early to go to } \\
\text { work, even with a hangover) }\end{array}$ & $484(72)$ & $20(74.1)$ & $41(73.2)$ & $.007(.934)$ & .009 \\
\hline 8 & $\begin{array}{c}\text { Do not use drugs to escape from } \\
\text { reality }\end{array}$ & $570(84.8)$ & $19(70.4)$ & $49(89.1)$ & $4,48(.034)$ & .22 \\
\hline 9 & $\begin{array}{l}\text { Consume only soft drugs like } \\
\text { cannabis }\end{array}$ & $235(35)$ & $14(51.9)$ & $25(45.5)$ & $.297(.586)$ & .06 \\
\hline 10 & $\begin{array}{c}\text { Do not use drugs alone, but with } \\
\text { others }\end{array}$ & $312(46.4)$ & $13(48.1)$ & $30(55.6)$ & $.39(.529)$ & .07 \\
\hline 11 & $\begin{array}{l}\text { Do not take drugs at home, always } \\
\text { somewhere else }\end{array}$ & $257(38.2)$ & $12(44.4)$ & $28(50)$ & $.225(.635)$ & .05 \\
\hline 12 & Reduce the amount of drugs & $596(88.7)$ & $22(81.5)$ & $52(92.9)$ & $2.43(.118)$ & .16 \\
\hline 13 & $\begin{array}{l}\text { Propose a limited quantity for each } \\
\text { day }\end{array}$ & $470(70)$ & $19(70.4)$ & $41(74.5)$ & $.161(.688)$ & .04 \\
\hline 14 & $\begin{array}{l}\text { Keep my mind occupied when I } \\
\text { want to take drugs }\end{array}$ & $635(94.5)$ & $25(92.6)$ & $54(96.4)$ & $.58(.445)$ & .08 \\
\hline 15 & $\begin{array}{l}\text { Do not go out with people who use } \\
\text { drugs or go to places where they are } \\
\text { taken }\end{array}$ & $562(83.6)$ & $21(77.8)$ & $55(98.2)$ & $9.85(.002)$ & .32 \\
\hline 16 & $\begin{array}{l}\text { Keep only the amount of drug to } \\
\text { take for one day; do not store at } \\
\text { home }\end{array}$ & $463(68.9)$ & $15(55.6)$ & $45(81.8)$ & $6.36(.012)$ & .26 \\
\hline 17 & $\begin{array}{l}\text { Think about the negative personal } \\
\text { and health consequences }\end{array}$ & $622(99.6)$ & $26(96.3)$ & $54(96.4)$ & $.001(.976)$ & .003 \\
\hline
\end{tabular}

Chi-square and contingency coefficient for variables ACU $(n=27)$ and GP $(n=56)$. ABU: Addictive Behavior Unit; GP: General Population.

It is interesting to note that the percentages of the general population both for Study 1 and 2 are very similar, taking into account the difference in the sample size $(n=672$ and $n=56$, respectively).

When comparing both subgroups of the Study 2, we can firstly see that differences in percentages were found according to relative frequencies.

To better analyse the obtained results, we opted to divide the percentages into three categories: low-frequency strategies, medium-frequency strategies, high-frequency strategies. We considered that those which obtained a percentage of $33 \%$ or lower were low-frequency strategies, those with a percentage between $33 \%$ and $66 \%$ were mediumfrequency strategies, and those with a percentage above $66 \%$ were high-frequency strategies. As a result, although the GP subgroup members indicated more highfrequency strategies (12) than the ABU subgroup members (9), the number of strategies indicated by the ABU subgroup is far from negligible, and they also indicate more medium-frequency strategies (8 vs. 4 in the GP group). 
The comparison of the frequencies and percentages between both groups provided highly relevant, but incomplete, information as expected frequencies were not taken into account. This was why a Chi-square test was carried out. In seven strategies significant results were obtained with both the Chi-square test and contingency coefficient. The GP subgroup members indicated these strategies with a significantly higher frequency than the ABU subgroup did. It is worth stressing these seven strategies: Strategy 1(Not taken on a daily basis); Strategy 3 (Do not sell drugs); Strategy 4 (Do not use drugs to overcome my problems or faults); Strategy 6 (Alternate drug use with other activities (walking, reading, etc.); Strategy 8 (Do not use drugs to escape from reality); Strategy 15 (Do not go out with people who use drugs or go to places where they are taken); Strategy 16 (Keep only the amount of drug to take for one day; do not store at home).

When we examined these seven strategies, we saw that apart from "Do not sell drugs" (Strategy 3), where we would expect GP subgroup members to respond much more favourably than ABU subgroup members, we could group the other six strategies into two groups: 1) restricting quantity, days when the drug is taken, and places and people, as well as seeking alternatives (strategies 1, 6, 15 and 16);2) not using drugs to sort out personal problems or to escape from reality (strategies 4 and 8 ). For the other strategies, the proportions of the responses between the two study groups were similar.

\section{Discussion}

This study provides some noteworthy results. In the first place, Study 1 replicates the results obtained previously in relation to the perception of control of drug use [26]. In the present study, with a larger and more diverse sample, the favourable view of using drug use control strategies was even higher $(n=72.7)$ than in the previous study $(n=65 \%)$.

For Study 2, of all the participants ( $n=147)$, slightly over half (56\%) considered that it was possible to control drug use by adopting certain strategies. We named this attitude "perception of control". In GP subgrup, 67.5\% agreed (two thirds of this group), which almost completely coincides with the first results obtained by [26], when $65 \%$ responded YES.

One novel aspect of the present study was that $32.5 \%$ of the drug users being treated in an $\mathrm{ABU}$ also answered YES. Although this percentage was slightly less than half those who answered YES in the GP group, it is interesting to verify that one third of those being treated for drug addiction considered it possible to control drugs.

The next significant result obtained in this study was to obtain a characteristic profile, related with higher perceived control, with the following variables: 1) belonging to the GP group; 2) being male; 3) being older; 4) having used cannabis sometime in one's life.

On the other hand, the strategies with the highest scores obtained for general population in both Study 1 and $2(1,4,8,12,14$ and 17 strategies) correspond perfectly with those obtained in the previous study [26]. This is an interesting and important result, since adding these samples $(n=1.721)$ we can say that we have identified the strategies most used by the general population, at least in the Mediterranean city of Valencia.

Finally, we can see that significant differences (Chi-square) were found between the two subgroups of the Study 2 for seven of the 17 evaluated strategies, and that the GP subgroup members pointed out these strategies more frequently. In short, we can state that the GP subgroup members considered it necessary to restrict drug use by bearing in mind places and people, and they also rejected using drugs to sort out personal problems 
or shortcomings. This indicates that perceived control in the GP is related with various kinds of control strategies, which are richer and ampler. The drug users being treated did not sufficiently consider the possibilities of strategically restricting drug use; perhaps use drugs as an emotional coping strategy. It has been previously verified for coping that $A B U$ group members use the drug resource and cognitive escape more, whereas GP members use cognitive coping with problems more $[29,30]$.

At this point, it would be most interesting to contemplate the implications that the results indicate to intervene in drug matters.

Firstly, we can state that GP members are more predisposed than drug users being treated to follow certain drug control use strategies that they can be proposed according to a drug abuse prevention program, and not from a total abstinence objective, but by moderating drug use. This would work particularly well for those who have taken cannabis, and are males and older individuals.

However, does this mean that programs to reduce or moderate drug use, as alternatives to abstinence, would not be useful for the other users (GP members and those being treated for their addiction)? We believe proposing the two alternatives would be most useful for the other drug users: 1) abstinence and zero drug use, or; 2) moderating drug use by following drug use control strategies. Similar strategies have been reported in a study into cocaine drug addicts, which showed that the coping strategies which related more with reduced drug use were "thinking about the negative consequences", "distractions", "alternative conducts", etc. [31].

This is true because we need to bear in mind that, as previously mentioned, one third of drug users being treated consider that controlled drug use is possible; moreover, the centers where they are being treated apply intervention programs to achieve abstinence. It is quite possible that if they were offered other alternatives, like moderate drug use, a higher percentage of drug addicts being treated would agree. However, this is a matter for future research.

With the drug users being treated, it will firstly be necessary to insist on setting rules for drug use to strategically restrict the quantity of drugs and the conditions under which they are taken (places, company, etc.); secondly, it would be necessary to teach them coping strategies for their problems, which would be alternatives to using drugs. In some treatments that promote moderate drug use, like the Brief Alcohol Screening and Intervention for College Students - BASICS) program [32], drug users are encouraged to adopt coping strategies to reduce risks [24, 33-36].

Training in using protective behavioural strategies for alcohol use has offered contradictory results. Although poorly satisfactory results have been obtained when applying only personalized and brief strategy training programs, they obtain clearly better results when they are prolonged in time or are extended with motivational interviews, social norms and group techniques [37-39].

Hence it is worth considering the potential use of strategies to control drug use as a fundamental component of drug use prevention programs, and to also treat drug users. There is some evidence that using drugs like heroin can be controlled to a certain extent [40]. Treatment programs that have been designed to apply control strategies with alcoholics and cocaine addicts have managed to reduce drug/alcohol use and relapses [see 41, for a review]. There is evidence to suggest that training programs for behavior control have been useful for opioid [42] and cannabis users [43]. 
A pilot study has tested the efficiency of an online program to reduce drug use by employing the 17 drug use control strategies by means of the DUSS [44]. The 14 drug users who completed treatment were able to significantly reduce their drug use by increasingly applying the proposed strategies.

This study has its limitations. It is necessary to increase the number of drug users being treated in this study, including drug users samples who are not being treated and others who have finished their rehabilitation programs. It would also be interesting to relate the perception of drug use control with other variables, like stress coping strategies, personality, attitudes to drugs, etc., which would provide a better understanding of the drug control perception. Evidence has been found for a relation between personality variables, such as sensation seeking and impulsiveness, and perception of control, and also with several of the 17 DUSS strategies [45-48]. The predictive profile of the favorable perception of drug control obtained in this study is a step in that direction.

\section{Conclusions}

Although these results are preliminary, the intervention to reduce drug use based on control strategies is an open research field. In such a hard and complex area like drug use and drug addiction, being able to rely on valid alternatives to abstinence programs can be extremely useful. This article is a step forward in this direction.

In this sense, the initial hypotheses have been confirmed. So, the result obtained in a previous study in the Spanish city of Valencia (65\% of the general population with a favourable view of the perception of drug use control and the use of strategies for it) has been replicated with an even larger sample, with an even higher percentage of $72.2 \%$.

On the other hand, we found a percentage of drug users with a lower perception of drug use control than in the general population, but significant one (32.5\%) and we have been able to identify drug use control strategies in which drug users in treatment and the general population coincide and differ.

All those results provide information about the perception of control and evaluate strategies for moderate drug use, thus offering valuable material for developing drug use risk and harm reduction programs.

Author Contributions: Conceptualization: S.A., Á.B., and J.Z.; Methodology: S.A., Á.B.; Formal Analyses: S.A.; Investigation: S.A., Á.B., and J.Z.: Supervision: Á.B; Writing-Original Draft Preparation: S.A.; Writing - Review and Editing: S.A., Á.B.

Funding: This research received no external funding.

Institutional Review Board Statement: The study was conducted in accordance with the Declaration of Helsinki, and the pro-tocol was approved by the Ethics Committee of the University of Valencia (Spain) in 2017 (Proyect identification code: H1484824011097).

Informed Consent Statement: Informed consent was obtained from all subjects involved in the study. Some variables are restricted to preserve the anonymity of study participants.

Data Availability Statement: The data presented in this study are available on request from the corresponding author.

Acknowledgments: The authors thank all of the participants in the study.

Conflicts of Interest: The authors declare no conflict of interest.

\section{References}

1. Zinberg, N.E; Harding, W.M. Control and intoxicant use: A theoretical and practical overview. Journal of Drug Issues 1979, 9, 121-143. https://doi.org/10.1177/002204267900900201 
2. Zinberg, N.E. Drug, set, setting. Yale U.P.: New Haven, USA, 1984.

3. Bielman, B.; Diaz, A.; Merlo, G.; Kaplan, C. D. Lines across Europe: Nature and extent of cocaine use in Barcelona, Rotterdam and Turin. Amsterdam: Swets and Zeitlinger, 1993.

4. Cohen, P. Shifting the main purposes of drug control: From suppression to regulation of use. Reduction of risks as the new focus for drug policy. International Journal of Drug Policy 1999, 10, 223-234.

5. Cohen, P.; Sas, A. Loss of control over cocaine, rule of exception? [Paper presentation] American Society of Criminology. New Orleans, USA, 1992, November 3-7.

6. Decorte T. The taming of cocaine: cocaine use in European and American cities. VUB University Press: Brussels, Belgium 2000 .

7. Decorte T.; Muys, M. Tipping the balance. A longitudinal study of perceived "pleasures" and "pains" of cocaine use. In Decorte T, Fountain J (Eds.), Pleasure, Pain and Profit. Pabst Wolfgang Science, 2010.

8. Erickson, P.G.; Weber, T.R. Cocaine careers, control and consequences: results from a canadian study. Addiction Research 1994, 2, 37-50. http://dx.doi.org/10.3109/16066359409005545

9. Hammersley, R.; Ditton, J. Cocaine careers in a sample of Scottish users. Addiction Research 1994, 2, 51-70.

10. https://doi.org/10.3109/16066359409005546

11. Mugford, S. K. Recreational cocaine use in three Australian cities. Addiction Research 1994, 2, 95-108. https://doi.org/10.3109/16066359409005548

12. Reinarman, C.; Murphy, S.; Waldorf, D. Pharmacology is not destiny: the contingent character of cocaine abuse and addiction. Addiction Research 1994, 2, 21-36. https://doi.org/10.3109/16066359409005544

13. Uitermark, J.; Cohen, P. Amphetamine users in Amsterdam. Patterns of use and modes of self-regulation. Addiction Research $\mathcal{E}$ Theory 2006, 14, 159-188. https://doi.org/10.1080/16066350500497934

14. Apsler, R. Measuring how people control the amounts of substances they use. In N. E. Zinberg, W. M. Harding (Eds.), Control over intoxicant use. Human Sciences Press, 1979, pp. 37-51.

15. Calafat A.; Fernández, C.; Juan, M, Bellis, M.A.; Bohrn, K.; Hakkarainen, P.; Kilfoyle-Carringto, M.; Kokkevi, A.; Maalsté, N.; Mendes, F.; Siamou, I.; Simon, J.; Stocco, P. \& Zavatti, P. Risk and control in the recreational drug culture. SONAR Proyect. IREFREA \& European Comission, 2001.

16. Cohen, P.; Sas, A.. Cocaine use in Amsterdam in non deviant subcultures. Addiction Research 1994, 2, 71-94. http://dx.doi.org/10.3109/16066359409005547

17. Hakkarainen, P. Huumausainekulttuuri ja käyttötavat Suomessa. Licentiate Thesis. University of Turku, Department of Sociology, 1987.

18. Waldorf, D.; Reinarman, C.; Murphy, S. Cocaine changes. The experience of using and quitting. Temple University Press: Philadelphia, USA, 1991.

19. Vadhan, N.P.; Hart, C.L.; Haney, M.; van Gorp, W.G.; Foltin, R.W. Decision-making in Long-Term Cocaine Users: Effects of a Cash Monetary Contingency on Gambling Task Performance. Drug and Alcohol Dependence 2009, 102, 95-101. https://doi.org/10.1016/j.drugalcdep.2009.02.003 
20. Lau, N.; Sales, P.; Averill, S.; Murphy, F.; Sato, S. O.; Murphy, S. Responsible and controlled use: Older cannabis users and harm reduction. The International Journal of Drug Policy 2015, 26, 709-718.

https://doi.org/10.1016/j.drugpo.2015.03.008.

21. Rodner, S. Practicing risk control in a socially disapproved area: Swedish socially integrated drug users and their perception of risks. Journal of Drug Issues 2006, 36, 933-951. https://doi.org/10.1177/002204260603600408

22. Martens, M.P.; Ferrier, A.G.; Sheehy, M.J.; Corbett, K.; Anderson, D.A.; Simmons A. Development of the Protective Behavioral Strategies Survey. Journal of Studies on Alcohol and Drugs 2005, 66, 698-705. https://doi.org/10.15288/jsa.2005.66.698

23. Treloar, H.T.; Martens, M.P.; McCarthy, D.M. The Protective Behavioral Strategies Scale-20: Improved content validity of the serious harm reduction subscale. Psychological Assessment 2015, 27, 340-346.

https://doi.org/10.1037/pas0000071

24. Martens, M.P.; Taylor, K.K.; Damann, K.M.; Page, J.C.; Mowry, E.S.: Cimini M.D. Protective behavioral strategies when drinking alcohol and their relationship to negative alcohol-related consequences in college students. Psychol Addict Behav. 2004, 18, 390-393. https://doi.org/10.1037/0893-164X.18.4.390

25. Martens, M. P.; Cimini, M. D.; Barr, A. R.; Rivero, E. M.; Vellis, P. A.; Desemone, G. A.; Horner, K. J. Implementing a screening and brief intervention for high-risk drinking in university-based health and mental health care settings: Reductions in alcohol use and correlates of success. Addictive Behaviors, 2007, 32, $2563-$ 2572. https://doi.org/10.1016/j.addbeh.2007.05.005

26. Martens, M.P.; Ferrier, A.G.; Cimini, M.D. Do protective behavioral strategies mediate the relationship between drinking motives and alcohol use in college students? Journal of Studies on Alcohol and Drugs 2007, 68, 106-114. https://doi.org/10.15288/jsad.2007.68.106

27. Amigó, S.; Martínez, A.; Báguena, M.J. Personality and strategies related to drugs consumption. [Paper presentation] $13^{\text {th }}$ European Conference on Personality. Athens, Greece, 2006, July 22-26.

28. Lin, S.; Zhang, Y. Risk control and rational recreation: A qualitative analysis of synthetic drug use among young urbanites in China. International Journal of Drug Policy 2014, 25, 769-775. https://doi.org/10.1016/j.drugpo.2014.06.008.

29. European Monitoring Centre for Drugs and Drug Addiction (EMCDA). 2003 Annual Report: The state of the drugs problem in the European Union and Norway, 2003. URL: https://www.emcdda.europa.eu/publications/annual-report/2003_en

30. Beleña, M.A.; Amigó, S. Estrategias de afrontamiento y de control del consumo de drogas en población general y drogodependientes en tratamiento [Coping strategies and drug use control in the general population and in drug addicts being treated] [Poster presentation] VI Jornada AIIDI. Santiago de Compostela, Spain, 2017, September 28-29.

31. López, J.J. Actitudes frente a las drogas y estrategias de control, de afrontamiento e impulsividad en pacientes de una Unidad de Conductas Adictivas y población general [Attitiudes to drugs and control and coping strategies, and impulsiveness in ACU patients and the general population] [Master Dissertation] Unpublished work. University of Valencia, Spain, 2012.

32. Rohsenow, D. J.; Martin, R. A.; Monti, P. M. Urge-specific and lifestyle coping strategies of cocaine abusers: Relationships to treatment outcomes. Drug and Alcohol Dependence 2005, 78, 211-219.

https://doi.org/10.1016/j.drugalcdep.2005.03.001

33. Dimeff, L. A.; Baer, J. S.; Kivlahan, D. R.; Marlatt, G. A. Brief alcohol screening and intervention for college students: A harm reduction approach. New York: NY: The Guilford Press, 1999. 
34. Baer, J. S.; Kivlahan, D. R.; Blume, A. W.; McKnight, P.; Marlatt, A. Brief intervention for heavy-drinking college students: 4-year follow-up and natural history. American Journal of Public Health 2001, 91, 1310-1316. https://www.researchgate.net/publication/6763323.

35. Borsari, B.; Carey, K. B. Effects of a brief motivational intervention with college student drinkers. Journal of Consulting and Clinical Psychology 2000, 68, 728-733. https://doi.org/10.1037/0022-006X.68.4.728

36. Larimer, M. E.; Turner, A. P.; Anderson, B. K.; Fader, J. S.; Kilmer, J. R.; Palmer, R. S.; Cronce, J. M. Evaluating a brief alcohol intervention with fraternities. Journal of Studies on Alcohol 2001. 62, 370-380. https://doi.org/10.15288/jsa.2001.62.370.

37. Marlatt, G. A.; Baer, J. S.; Kivlahan, D. R.; Dimeff, L. A.; Larimer, M. E.; Quigley, L. A.; Somers, J.M.; Williams, E. Screening and brief intervention for high-risk college student drinkers: Results from a 2-year follow-up assessment. Journal of Consulting and Clinical Psychology 1998, 66, 604-615. https://doi.org/10.1037//0022006x.66.4.604

38. Kenney, S. R.; Napper, L. E.; LaBrie, J. W.; Martens, M. P. Examining the efficacy of a brief group protective behavioral strategies skills training alcohol intervention with college women. Psychology of Addictive Behaviors 2014, 28, 1041-1051. https://doi.org/10.1037/a0038173.

39. LaBrie, J. W.; Napper, L. E.; Grimaldi, E. M.; Kenney, S. R.; Lac, A. The efficacy of a standalone protective behavioral strategies intervention for students accessing mental health services. Prevention science: the official journal of the Society for Prevention Research 2015, 16, 663-673. https://doi.org/10.1007/s11121-015-0549-8.

40. Martens, M.P.; Smith, A.E.; Murphy, J.G. The efficacy of single-component brief motivational interventions among at-risk college drinkers. Journal of Consulting and Clinical Psychology 2013, 81, 691-701. https://doi.org/10.1037/a0032235

41. Harding, G. Patterns of heroin use: what do we know? British of Journal Addiction 1988. 83, 1247-1254. https://doi.org/10.1111/j.1360-0443.1988.tb03035.x

42. Monti, P. M.; O'Leary, T. A. Coping and social skills training for alcohol and cocaine dependence. Psychiatric Clinics of North America 1999, 22, 447-470. https://doi.org/10.1016/S0193-953X(05)70086-1

43. Van Bilsen, H.P.; Whitehead, B. Learning controlled drugs use: a case study. Behavioural and Cognitive Psychotherapy 1994, 22, 87-95.

44. Lozano, B.E.; Stephens, R.S.; Roffman, R.A. Abstinence and moderate use goals in the treatment of marijuana dependence. Addiction 2006, 101, 1589-1597. https://doi.org/10.1111/j.1360-0443.2006.01609.x

45. García, M. Consolidación de una página web orientada al aprendizaje de estrategias de control en el consumo de drogas [Consolidated website about learning drug use control strategies] [Master Dissertation] University of Valencia, Spain, 2015.

46. Amigó, S.; Beleña, M.A. Impulsividad y percepción del control del consumo de drogas [Impulsiveness and perception of drug use control] [Paper presentation]. VI Jornada AIIDI. Santiago de Compostela, Spain, 2017, September 28-29.

47. Amigó, S.; Martínez, D.; Díaz, A. Predisposición a la violencia y estrategias de consumo controlado de drogas [Predisposition to violence and controlled drug use strategies] [Paper presentation] VI Congreso Español de Criminología “Criminalidad y Riesgo: Predicción y Prevención”. Santiago de Compostela, Spain, 2009, June $18-20$. 
48. Amigó, S.; Portaceli, J. La juventud universitaria y las drogas. Encuesta sobre drogas en la Universidad Politécnica de Valencia (curso 2001/2002) [University youths and drugs. Survey on drugs at the Polytechnic University of Valencia (academic year 2001/2002)] The UPV Publishing House, Valencia, Spain, 2002.

49. Beleña, M.A.; Amigó, S. Impulsividad y percepción del control del consumo de drogas [Impulsiveness and perception of drug use control] [Poster presentation] VI Jornada AIIDI. Santiago de Compostela, Spain 2017, September 28-29. 